\section{Neonatal hemophilia: a rare presentation}

\author{
Nuno Ferreira, ${ }^{1}$ Elisa Proença, ${ }^{1}$ \\ Cristina Godinho,1 Dulce Oliveira, 1 \\ Ana Guedes, 1 Sara Morais,2 \\ Carmen Carvalho ${ }^{1}$
}

1Neonatal Intensive Care Unit, ${ }^{2}$ Clinical

Hematology Department, Centro

Hospitalar do Porto, Portugal

\section{Abstract}

Hemophilia A is a X-linked hereditary condition that lead to decreased factor VIII activity, occurs mainly in males. Decreased factor VIII activity leads to increased risk of bleeding events. During neonatal period, diagnosis is made after post-partum bleeding complication or unexpected bleeding after medical procedures. Subgaleal hemorrhage during neonatal period is a rare, severe extracranial bleeding with high mortality and usually related to traumatic labor or coagulation disorders. Subgaleal hemorrhage complications result from massive bleeding. We present a neonate with unremarkable family history and uneventful pregnancy with a vaginal delivery with no instrumentation, presenting with severe subgaleal bleeding at 52 hours of life. Aggressive support measures were implemented and bleeding managed. The unexpected bleeding lead to a coagulation study and the diagnosis of severe hemophilia A. There were no known sequelae. This case shows a rare hemophilia presentation reflecting the importance of coagulation studies when faced with unexplained severe bleeding.

\section{Introduction}

Hemophilia is an hereditary coagulopathy linked to X-chromosome which mainly affects male individuals. ${ }^{1}$ It can be either hemophilia A or B depending whether there is a decrease of factor VIII or IX. It has an incidence of 1 per 5000 male births. ${ }^{2}$ Hemophilia A is the most common type accounting for $85 \%$ of the cases. ${ }^{2}$ It is suspected by an unexpected bleeding event with isolated prolonged activated partial thromboplastin time (APTT) on coagulation studies. ${ }^{3}$ The diagnosis is made by decreased plasmatic factor VIII or IX activity, after testing other coagulation factors (including von Willebrand factor). ${ }^{4}$ Its severity depends on the factor activity and correlates with clinical features, being severe hemophilia a significant risk for spontaneous bleeding, ${ }^{2}$ and cranial hemorrhage (3.5 to $4 \%$ of hemophilic patients). ${ }^{5}$ After diagnosis of hemophilia, treatment for acute bleeding should be undertaken urgently with FVIII or FIX concentrates. Despite being an hereditary condition it has a significant rate of de novo mutations, which could go from 30 to $50 \%$.1,6 Nowadays, major hemophilia problems are life-threatening bleeding and inhibitor development. ${ }^{7}$

When there is known family history, usually the diagnosis is made during the neonatal period. ${ }^{8}$ A significant hemostatic challenge like surgery, major trauma or labor, can represent a high bleeding risk.6,9,10 Neonatal hemophilia presentation is usually either related to a traumatic labor (intracranial hemorrhage and cephalohematoma) or to iatrogenic bleeding during heel stab sampling, venous puncture or vitamin $\mathrm{K}$ administration. ${ }^{3}$ Rarely neonatal hemophilia presents with subgaleal hemorrhage and it carries a high mortality risk due to severe bleeding. ${ }^{11}$ Hemophilic patients may remain undiagnosed during neonatal period. ${ }^{6}$ Better treatment strategies centered on recombinant factors replacement lead to a considerable decrease on mortality rates for hemophilia in last years, with recent studies showing a nearly normal life expectancy even in severe hemophilia. ${ }^{12,13}$ Our aim is to describe an unknown severe hemophilia in a neonate presenting a subgaleal hemorrhage.

\section{Case Report}

Male, black newborn, with healthy and unrelated parents, and no known hereditary or hematological conditions. All obstetric workup was normal. The current gestation was uncomplicated, with a vaginal delivery at 39 weeks, with no complications. At first exam he had an Apgar index of 9 at first minute and 10 at five minutes. Birth weight of 3840 grams (heavy for gestational age), height: $50.5 \mathrm{~cm}$ and head circumference: $35 \mathrm{~cm}$. No dimorphism detected and there were no traumatic lesions. He was transferred with his mother to obstetrics ward for regular neonatal care. Vitamin $\mathrm{K}$ was administered at birth and breastfeeding was started. At 52 hours of life he was urgently assessed for marked pallor and severe palpebral edema. At physical examination he presented with scarcely active, with low pitched crying, poor perfusion, heart rate of $135 \mathrm{bpp}$, normal blood pressure $(81 / 47 \mathrm{mmHg})$, normal oxygen saturation, with normal pulmonary and cardiac examination. He had marked irregular scalp edema with a retro auricular hematoma. There was a $4 \mathrm{~cm}$ increase on head circumference $(39 \mathrm{~cm})$. There were no other changes on physical examination, namely signs of hemorrhagic diathesis. No history of trauma or fall. He was transferred to neonatal intensive care
Correspondence: Nuno Alexandre Pacheco Ferreira, Neonatal Intensive Care Unit, Centro Hospitalar do Porto, Avenida Pedro Guedes, n 651, $2^{\circ}$ esquerdo traseiras, 4560-452, Penafiel, Porto, Portugal.

Tel.: +351.916.620070

E-mail: nuno.ap.ferreira@gmail.com

Key words: Hemophilia A; subgaleal hemorrhage; neonate; extracranial bleeding.

Contributions: the authors contributed equally.

Conflict of interest: the authors declare no potential conflict of interest.

Received for publication: 30 November 2015

Accepted for publication: 17 December 2015

This work is licensed under a Creative Commons Attribution NonCommercial 3.0 License (CC BYNC 3.0).

(C) Copyright N. Ferreira, et al., 2015

Licensee PAGEPress, Italy

Pediatric Reports 2015; 7:6338

doi:10.4081/pr.2015.6368

unit and a full blood count, coagulation study, blood chemistry and blood culture were performed. The blood count was consistent with severe anemia (hemoglobin: $6.6 \mathrm{~g} / \mathrm{dL}$ ) and coagulation studies revealed a prolonged APTT and a pro-thrombin time not coagulable, interpreted as an inadequate sample which was repeated to show an isolated prolonged APTT. Factor VIII, IX, XIII and vWF were measured, with a very low factor VIII activity $(<1 \%)$ which was compatible with severe hemophilia. Blood chemistry was unremarkable at first with a steady increase in indirect bilirubin.

Cerebral ultrasound at day 1 showed enlarged pericerebral space, with a bad differentiation of structures, with no apparent intracranial hemorrhage. Head computed tomography (CT) scan showed extensive bilateral subgaleal hematomas and no images compatible with intracranial bleeding. It also showed no signs of cranial fractures. Meantime he started saline bolus ( $20 \mathrm{~mL} / \mathrm{kg})$, erythrocyte transfusion $(15 \mathrm{~mL} / \mathrm{kg})$, intravenous vitamin $\mathrm{K}$ and adequate analgesia.

After the diagnosis, recombinant factor VIII concentrate $(50 \mathrm{IU} / \mathrm{Kg}$ ) was started. There was no further progression of the subgaleal bleeding with slow decrease in head circumference. He kept hemodynamic and cardio-respiratory stability. He was under phototherapy for jaundice during 72 hours (maximum of $18.4 \mathrm{mg} / \mathrm{dL}$ total bilirubin).

He was discharged on day 11 of life with a resolving subgaleal hemorrhage, head circumference of $36.8 \mathrm{~cm}$. He was referred to both neonatology and hematology follow up clinics. 
Since discharge he had 2 minor bleeding episodes (thoracic wall and right knee subcutaneous hematomas) requiring a single dose of factor VIII at each event. He will start FVIII prophylaxis after the first hemarthroses.

Currently he is 8 months old and had no further clinical relevant complications up to date.

\section{Discussion}

This case shows a severe subgaleal hemorrhage as a presentation of a severe hemophilia. Despite hemophilia being a known risk factor for cranial bleeding, we found no record of a similar presentation after an uncomplicated vaginal delivery and with no traumatic history or family history of coagulopathy. Our patient presented with anemia, lethargy and preshock, the most common presentation in hemophilic patients with cranial bleeding. ${ }^{5} \mathrm{He}$ had a severe subgaleal hemorrhage with an increase in $4 \mathrm{~cm}$ on head circumference and jaundice and required a saline bolus and packed red cells transfusion. ${ }^{14}$ According to Plauché et al., $1 \mathrm{~cm}$ increase on head size can relate to at least $40 \mathrm{~mL}$ bleeding. 15,16 If we bare in mind that the total circulating blood of a neonate is around $80 \mathrm{~mL} / \mathrm{kg}$ a $4 \mathrm{~cm}$ increase on head size represents at least a blood loss of 160 $\mathrm{mL}$ bleed (52\% of total volume). ${ }^{17}$ According to literature, coagulation studies should be made as soon as possible under a suspicion of consumption coagulopathy. 18 When present, disseminated intravascular coagulopathy seems to represent a sign of poor prognosis. ${ }^{19}$

We focused our approach on aggressive correction of hypovolemic shock with saline bolus and red cell transfusion, according to the existent literature. ${ }^{20}$ Inotropes and vasopressors may also be used.

High mortality rates of subgaleal hemorrhage are related to delays on diagnosis, misdiagnosis and inadequate monitoring and treatment. ${ }^{18}$ So early recognition, careful monitoring and aggressive treatment were important to improve outcome.

As recommended by literature head imaging with a CT scan was made as soon as possible to assess the size of bleeding and related complications or co-morbidities.18 Head magnetic resonance would be the preferred imaging method, ${ }^{18}$ but was not promptly available.

Complications related to subgaleal hemorrhage and hypoxic ischemic encephalopathy can complicate up to $72 \%$ of the cases.14 Development delay and cerebral palsy are the main complications, ${ }^{18}$ however outcome of survivors is usually good, with a maximum described disability incidence of $33 \% .{ }^{19}$ At this moment our patient shows a normal development.

In severe hemophilia, the prevention of bleeding by prophylactic therapy is now advocated. The optimal treatment regimen for prophylaxis is debatable (when to start and which dose). Long term treatment strategies for hemophilia vary, with more studies suggesting a prophylactic treatment for severe cases of hemophilia A and an on demand treatment should be considered for mild and moderate cases. ${ }^{4}$ Most of these studies are not conducted on neonates and small children for whom there is scarce information about the ideal treatment plan. According to the hematology department we decided to maintain our patient with on demand treatment, until the first hemarthroses.

\section{Conclusions}

After reviewing existent literature we conclude that our patient had a rare presentation of hemophilia. He presented a subgaleal hemorrhage after an uncomplicated vaginal delivery. Aggressive support treatment was effective on controlling initial bleeding and preventing shock. Hemophilia diagnosis was made within 12 hours after presentation and treatment towards hemophilia A started, with no other bleeding episodes during inpatient stay. Imaging studies showed no other complications from the initial presentation and a normal neurodevelopment was achieved up to date. This case report reminds that hemophilia can present in several different ways. When facing a significant bleeding on a neonate with no risk factors, a blood coagulation disorder must be thought along with immediate aggressive support measures. An early diagnosis allows to an early directed treatment and better outcome.

\section{References}

1. Gianelli F, Green PM. The molecular basis of haemophilia A and B. Baillieres Clin Haematol 1996;9:211-8.

2. Orkin SH, Nathan DG, Ginsberg D, et al, eds. Nathan and Oski's hematology of infancy and childhood. 7 ed. Philadelphia: WB Saunders; 2009.

3. Chalmers E, Williams M, Brennand J, et al. Guideline on the management of haemophilia in the fetus and neonate. Br J Haematol 2011;154:208-15.

4. Nagel K, Pai MK, Paes BA, Chan AK. Diagnosis and treatment of intracranial hemorrhage in children with haemophilia. Blood Coagul Fibrinol 2012;24:23-7.

5. Ljung RCP. Intracranial haemorrhage in haemophilia $\mathrm{A}$ and $\mathrm{B}$. $\mathrm{Br} \mathrm{J}$ Med 2007;140:378-84.
6. Ljung R, Chambost H, Stain AM, Dimichele D. Haemophilia in the first years of life. Haemophilia 2008;14:188-95.

7. Ljung $R$, Chambost $H$, Stain AM, DiMichele D. Haemophilia in the first years of life. Haemophilia 2008;14:188-95.

8. Ljung R, Petrini P, Nilsson IM. Diagnostic symptons of severe and moderate haemophilia A and B. A survey of 140 cases. Acta Paediatr Scand 1990:79:196200.

9. Richards M, Fijnvandraat K, LavigneLissalde G. A European study of major neoanatal haemorrhage in haemophilia. J Thromb Haemost 2009;7:99.

10. Tarantino MD, Gupta SL, Brusky RM. The incidence and outcome of intracranial haemorrhage in newborns with haemophilia: analysis of the nationwide inpatient sample database. Haemophilia 2007;13:380-2.

11. Doumouchtsis SK, Arulkumaran S. Head trauma after instrumental births. Clin Perinatol 2008;35:69-83.

12. Darby SC, Kan SW, Spooner RJ, et al. Mortality, life expectancy and causes of death in people with haemophilia A and B in the United Kingdom who were not infected with HIV. Blood 2007;110:815-25.

13. Mejia-Carvajal C, Czapek EE, Valentino LA. Life expectancy in hemofilia outcome. J Thromb Haemost 2006;4:507-9.

14. Chadwick LM, Pemberton PJ, Kurinczuk JJ. Neonatal subgaleal haematoma: associated risk factors, complications and outcome. J Paediatr Child Health 1996;32:22832.

15. Plauché WC. Subgaleal hematoma: a complication of instrumental delivery. JAMA 1980;244:1597-8.

16. Eliachar E, Bret AJ, Bardiaux M, et al. Hématome souscutané cranien du nouveau-né. Arch Fr Pediatr 1963;20:1105-11.

17. Nagano K, Kusaka T, Okubo K, et al. Estimation of circulating blood volume in infants using the pulse dye densitometry method. Paediatr Anaesth 2005;15:125-30.

18. Colditz MJ, Lai MM, Cartwright DW, Colditz PB. Subgaleal haemorrhage in the newborn: a call for early diagnosis and aggressive management. J Paediatr Child Health 2015;51:140-6.

19. Chang HY, Peng CC, Kao HA, et al. Neonatal subgaleal hemorrhage: clinical presentation, treatment, and predictors of poor prognosis. Pediatr Int 2007;49:903-7.

20. Schierholz E, Walker SR. Responding to traumatic birth: subgaleal hemorrhage, assessment, and management during transport. Adv Neonat Care 2010;10:311-5. 